
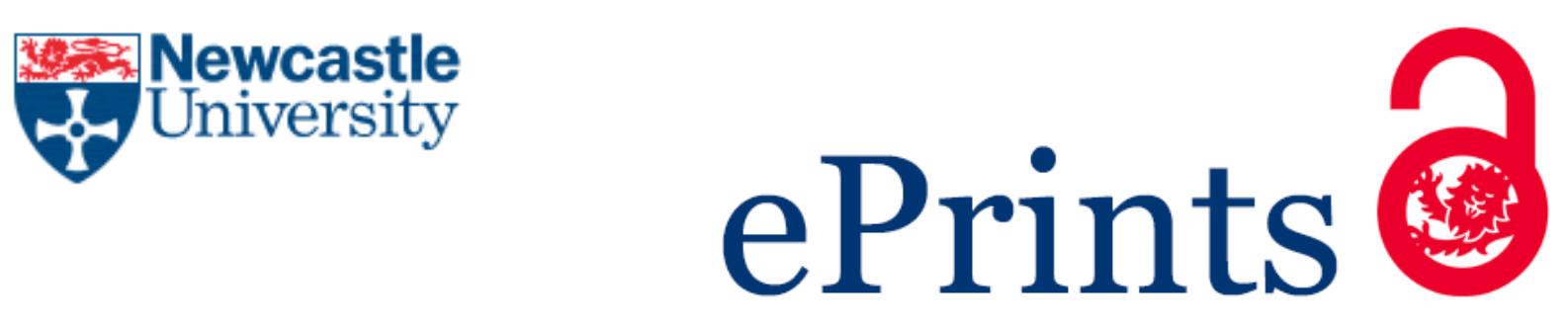

Guo CD, Feng HH, Jia BR, Zuo ZX, Guo YY, Roskilly AP.

Research on the operation characteristics of a free-piston linear generator:

Numerical model and experimental results.

Energy Conversion and Management 2017, 131, 32-43.

\title{
Copyright:
}

(C) 2017. This manuscript version is made available under the CC-BY-NC-ND 4.0 license

DOI link to article:

https://doi.org/10.1016/i.enconman.2016.11.010

Date deposited:

$27 / 06 / 2017$

Embargo release date:

11 November 2017

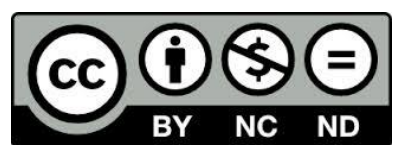

This work is licensed under a

Creative Commons Attribution-NonCommercial-NoDerivatives 4.0 International licence 


\section{Research on the operation characteristics of a free-piston linear generator: Numerical model and experimental results}

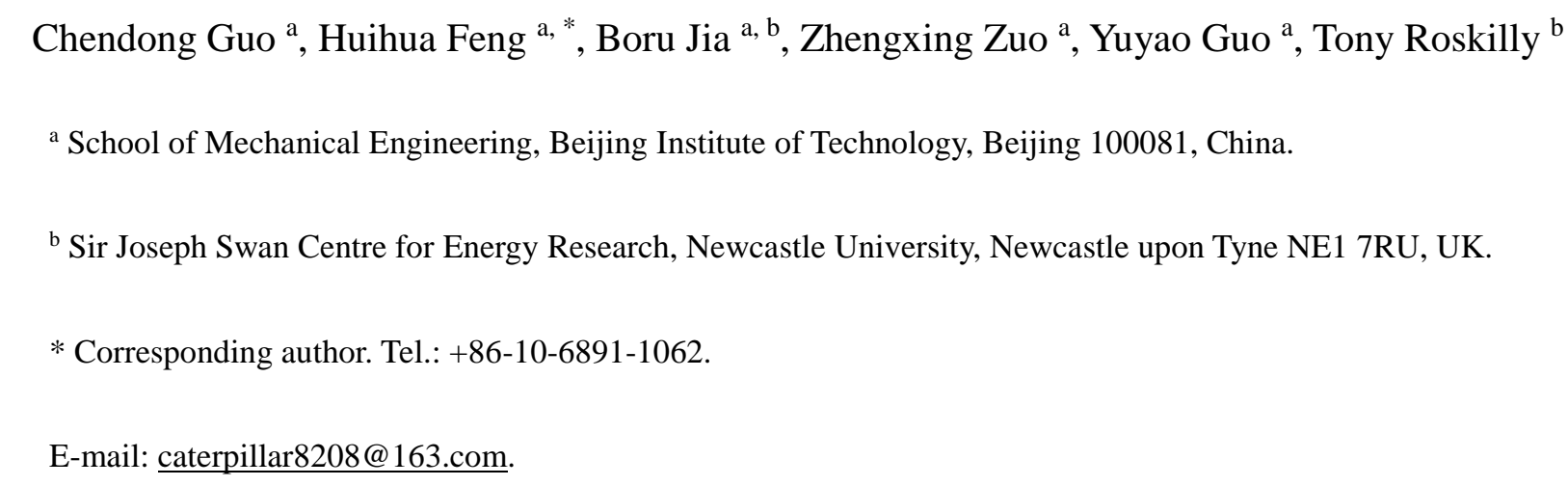

Abstract: Free piston linear generator (FPLG) shows unique operation characteristics due to the elimination of crankshaft and connecting rod mechanism. This paper investigates its operation characteristics during each operating process based on the simulation and experiment results. During the starting process, the larger motor force during the starting process, the fewer times of reciprocating pistons which meet the condition of ignition. When the motor force reached $300 \mathrm{~N}$, the prototype could adopt one-stroke starting strategy. During the intermediate process, it was found that the "gradually switching strategy" could help to achieve a smoother operation during the intermediate process. And the values of the operation parameters after the intermediate process were lower than those before the intermediate process. During the generating process, cycle-to-cycle variations were observed for piston TDC and in-cylinder gas pressure from the experimental results. According to the experimental results of the FPLG during the generating process, the calculated engine indicated power is $2.9 \mathrm{~kW}$, and the corresponding indicated thermal efficiency is $37.3 \%$. Additionally, based on the comparison of the FPLG performance, it is found that the parameters of the FPLG during the generating process are smaller than those when it was operated during the second stage of the starting process, while much higher than those during the first stage of the starting process. 
24 Keywords: Free-piston linear generator; the operation process; piston dynamics; FPLG performance

\section{Introduction}

The free-piston linear generator (FPLG), as a new energy conversion appliance, is a combination of free-piston engines and a linear electric machine (LEM) [1-5]. The general working principle of the FPLG is that the high-temperature and high-pressure gas are generated during the heat release process in the cylinder, then the gas drives the piston and connecting rod to reciprocate, and the LEM converts parts of the mechanical energy into electricity [6]. Compared with the traditional reciprocating engine (TRE), the FPLG is a kind of crankless engine. As a result it shows various potential advantages, such as variable compression ratios, short energy convertion chains, multi fuel feasibility, and simplified structure since the crankshaft mechanism is eliminated [7-9]. Therefore, the global researchers have strong interest in the FPLG.

The concept of the free-piston engine was first proposed by Pescara as a patent in 1928 [10]. After that, there were a few representative products, such as the free piston compressor and free piston gasifier [11]. However, research on the free-piston engine progressed slowly because of the limited technological conditions at that time $[1,4,9]$. Nowadays, with the rapid development of technology in recent years, many research institutes have begun to study the free-piston engine again, and the free-piston engine development progressed fast.

The research group from West Virginia University have researched on FPLG since 1995. They conducted numerical simulation for the operation process, and studied the influences of different parameters on the system characteristics [12-17]. And the prototype consisted of two two-stroke free-piston engines. Results indicated that without external load, the operation frequency of the prototype was $1457 \mathrm{rad} / \mathrm{min}$, and the piston motion profile was similar to the sinusoidal state. When 
the prototype was loaded, its operation frequency was $1361 \mathrm{rad} / \mathrm{min}$, and the maximum output power was $316 \mathrm{~W}$. However, the prototype generation efficiency was low, and the machine could not operate continuously.

The research group from the Sandia National Laboratory (SNL) designed a FPLG prototype from 2000 [18-19]. The prototype showed high efficiency, low emission and was able to operate on a variety of hydrogen-containing fuels. The FPLG employed a homogeneous charge compression ignition (HCCI) mode, and the thermodynamic cycle achieved was close to the Otto cycle. The research group from Czech Technical University developed two FPLG prototypes in 2003 and 2007 respectively [20-23]. Experiment results indicated that the operation frequency of the first prototype was $27 \mathrm{~Hz}$, and the maximum output power was $650 \mathrm{~W}$. However, the systematic generation efficiency was less than $10 \%$.

In 2002, the EU Energy Commission started the Free Piston Energy Converter (FPEC) program [24-25], aiming to apply the HCCI method on the FPEC. They conducted coupling numerical simulation of the operation process of the FPEC [26]. Results suggest that the fuel with low octane number needs high compression ratio, and the high compression ratio will increase the operation frequency, output power and efficiency of the FPEC. And they designed a prototype with an output power of $25 \mathrm{~kW}$, and power intensity larger than $0.6 \mathrm{~kW} / \mathrm{kg}$, which was expected to meet the European $\mathrm{V}$ discharge standard. However, most of the parameters and engine operation characteristics were simulation results, and very few experiment data were reported.

The research group at Newcastle University began the investigation of the FPLG from 2005 [27-33]. Numerical modelling was conducted to study the characteristics of the internal combustion engine of the FPLG, piston dynamics, and the controlling system. Simulation results suggested that 
the FPLG operation frequency was $30 \mathrm{~Hz}$, the output power was $44.4 \mathrm{~kW}$, and its efficiency was up to $42 \%$. Compared with the TRE, FPLG showed higher efficiency and lower gas temperature, so as to reduce the NOx emission. Besides that, it was found that the FPLG was very sensitive to load, and the system was easy to reach satisfactory results by using simple controlling strategy. However, most of their work was reported on the numerical simulation analysis.

Researchers from Nanjing University of Science and Technology did research on a single-piston free-piston engine linear generator [34-35]. They designed a prototype and the experiment results indicated that the output power was $2.2 \mathrm{~kW}$ and the heat efficiency reached $32 \%$. They designed the controller of stratification of single-piston free-piston linear generator. Its main concept was to modify the piston motion through controlling the electronic magnets so as to ensure that the prototype was able to operate consecutively.

Researchers at the Beijing Institute of Technology have been studying the FPLG since 2006, and several prototypes have been designed [1, 6-8, 36-41]. They conducted zero-numerical simulation of FPLG and predicted the operation frequency of the FPLG, and the dynamics of the piston. They have analyzed the influence of main parameters of the scavenging system on the scavenging efficiency, and the influence of piston motion on the engine combustion process. Experimental results suggested that the peak in-cylinder gas pressure was above 40 bar for the first prototype, and the operation frequency was $30 \mathrm{~Hz}$. The second prototype of the FPLG could operate stably during the starting process from the papers. Experimental results showed that during the starting process, the peak in-cylinder pressure and compression ratio increased in a non-linear manner and tended to reach a stable state after several operation cycles. After successfully ignition, the peak piston velocity increased significantly to approximately $4.0 \mathrm{~m} / \mathrm{s}$. 

two-stroke combustion chamber, a linear generator, and a gas spring chamber [42-43]. Experimental results showed that the prototype operated stably for quite a long period of time, despite of the abnormal combustion during the test. And the researchers have analyzed the unique piston motion, which poses its effects on combustion and power generation in the FPLG.

From the discussion above, it is found that researchers from all over the world mainly focused on the simulation of the piston dynamics and the FPLG performances during the generating process, the experimental investigation of the FPLG during the starting process [6]. Very few studies have been reported on the operation characteristics of the FPLG during the operation process, including the starting process, the intermediate process (from the engine cold start-up to stable operation process) and the generating process. Therefore, in this paper, the operation characteristics of the FPLG during each operation process will be investigated based on both simulation and experimental results. As for the starting process, the influences of different motor forces on the FPLG were analyzed. In terms of the intermediate process, the influences of different switching strategies on the FPLG were compared. And during the generating process, the piston dynamics and the FPLG characteristics were investigated. This study provides a useful guidance for the design and control of the operation process of the FPLG, especially research on the experiment investigation of the FPLG.

\section{Fundamentals of the FPLG system}

\subsection{FPLG prototype configuration}

From the literatures, it is observed that the FPLG can be generally divided into three types according to the differences in the number of free-pistons and distribution patterns: namely the single-piston single-cylinder type, the dual-piston dual-cylinder type, and the opposed dual-piston 
112 single-cylinder type [6]. Compared to the other two kinds of types, the dual-piston and dual-cylinder

113 type are widely used due to its advantages over the relatively comprehensive performance, i.e. the

114 high power to weight ratio and elimination of rebound device, compact size [4]. Therefore, a 115 dual-piston dual-cylinder type FPLG is adopted in this research. The main structure of the designed 116 FPLG is shown in Figure 1. And the FPLG prototype is demonstrated in Figure 2. This prototype 117 employs a dual piston, two-stroke, spark-ignited, engine with uniflow scavenging process. And the 118 prototype is including the LEM system, the air-intake system, the fuel injection system, the ignition 119 system, the controlling system and test system [8, 44-46]. The specifications of the prototype are 120 summarized in Table 1. processes: the starting process, the intermediate process from start-up to stable operation, and the stable generating process. The three processes are illustrated in Figure 3. The first process is the starting process during which the LEM runs as a motor supplying constant force to the piston and connecting rod, and the force in the same direction with piston velocity. The starting process involves two stages. In the first stage, the motor drives the piston and connecting rod oscillates until it reaches the required conditions for ignition. During the second stage, the mixed gas in the cylinder combusted alternatively until it stabilized under the condition that the LEM also runs as a motor. The starting process is completed, the LEM will be switched to generator mode during the intermediate process. The third process was the stable generating process during which the LEM ran as a generator. The mixed gas in cylinder combusted alternatively to drive the piston and connecting rod 
to reciprocate, and the LEM converts parts of the kinetic energy into electricity [6].

\subsection{FPLG prototype control strategy}

From the discussion above, it is found that the prototype including the LEM system, the air-intake system, the fuel injection system, the ignition system, the control system and test system. The FPLG during the operation process is coupled with proper control strategies. And all these sub-control-systems are integrated in the integrated electronic control unit (ECU) [8].

As for the LEM subsystem, it consists of four components: the LEM, the LEM controller, the driver and the controlling software which controls the LEM working mode (the LEM runs as a motor or a generator). Based on the working principle of the LEM, during the starting process the LEM uses the PID compensation control strategy to supply a constant motor force to piston and the motor force in the same direction with piston velocity. During the intermediate process, the LEM controller control over the switching of the LEM working mode. During the generating process, the LEM supplies a resistance force to piston and the force in the opposite direction of the piston velocity, because the LEM exports electric energy to the load resistance [8].

As for the ignition subsystem, this experiment platform used a high-energy ignition device controlled by a microcomputer in the ignition system. In order to eliminate the negative influences of ignition energy on the operation process of the FPLG, the ignition pulse was more than 2 ms to ensure ignition energy above $100 \mathrm{~mJ}$. The principle of the ignition control system was that when the piston reached a predesigned displacement, which was at $\mathrm{X} 1(-\mathrm{X} 1)$ displacement from centre, the ECU sent a signal to the ignition system. The logic diagram of the ignition control program, as shown in Figure 4 illustrates.

As for the fuel injection subsystem, the port fuel injection (PFI) was applied during the 
experiment platform. The principle of the injection control system is that when the piston reached a predesigned displacement, which was at X1 (-X1) displacement from the centre, the ECU sent a signal to the ignition system. According to the characteristics of this experiment platform, the fuel and air went through the intake and scavenging box into the gas cylinder. In order to mix the fuel and 160 air completely, it was the optimal timing for the fuel in the left cylinder to be injected when the 161 piston was at the ignition timing of the right cylinder, and vice versa. The logic diagram of the fuel 162 injection control program is shown in Figure 4. The fuel injection pulse of both the left and right 163 cylinders was the same, which measured the air mass that flew in the system at each cycle through 164 the flow meter in the air-intake system. Open-loop control was carried out based on the theoretical air-fuel ratio of 14.7.

The controlling and test system of the prototype is illustrated in Figure 5. The FPLG's data testing system in this experiment contains a data collection card, various sensors, and data collection software based on LabVIEW software to collect accurate data in the FPLG experiment. The data collection card in the experiment is the PXI Express data collection system. In addition, the experiment used the $6052 \mathrm{C}$ pressure sensor to record the in-cylinder gas pressure. The sensor within the LEM can detect the displacement of a magnetic pole to calculate the displacement of piston that 172 can obtain the velocity value through the differential method. And the resolution of the encoder is 173400 microns. The output signals not only can be used as the input signals of the ECU, they can also 174 store data for further study on the dynamics of the piston and the operation characteristics of the FPLG $[1,6,8]$. 


\section{Model description and validation}

$$
\begin{cases}m \frac{d^{2} x}{d t^{2}}=\left(p_{L}-p_{R}\right) A-F_{f}+F_{m} \cdot \operatorname{sign}\left(\frac{d x}{d t}\right), & \text { The starting process } \\ m \frac{d^{2} x}{d t^{2}}=\left(p_{L}-p_{R}\right) A-F_{f}+\varepsilon_{1}(n) F_{m} \cdot \operatorname{sign}\left(\frac{d x}{d t}\right)-\varepsilon_{2}(n) F_{g} \cdot \operatorname{sign}\left(\frac{d x}{d t}\right), & \text { The intermediate process } \\ m \frac{d^{2} x}{d t^{2}}=\left(p_{L}-p_{R}\right) A-F_{f}-F_{g} \cdot \operatorname{sign}\left(\frac{d x}{d t}\right), & \text { The generator process }\end{cases}
$$

\subsection{Model description}

In order to explore the performance of the FPLG during the operation process, the numerical model which is governed by the Newton's second Law is established (as shown in Figure 6).

Based on the working principle of the FPLG, the starting process of the FPLG, the LEM supplies a constant motor force to piston and the force in the same direction with piston velocity. During the generating process, the LEM supplies a resistance force to piston and the force in the opposite direction of the piston velocity. Because the constant gas pressure from the left and right scavenging pump, the joint force is zero [9]. Therefore, the dynamics equation of the piston is expressed as follows [6]:

where, $m$ is the mass of the piston and connecting rod, $x$ is the piston's displacement, $A$ is the top surface area of the piston, $p_{L}$ and $p_{R}$ represent the pressure in both the left and right cylinder respectively, $F_{f}$ is the friction force, $F_{m}$ is a constant motor force when the LEM runs as a motor, $F_{g}$

190 is the a resistance force when the LEM is operated as a generator. $\frac{d x}{d t}$ is the piston velocity, and $191 \operatorname{sig} n\left(\frac{d x}{d t}\right)$ means the direction of piston velocity. $\varepsilon_{1}(x)$ and $\varepsilon_{2}(x)$ are step functions. 
where, $x_{1}$ is the switching position.

According to our previous publications that research on the intermediate process of FPLG [6],

196 the gradually switching strategy means the motor force of the LEM decreases gradually from $100 \%$

197 to $50 \%$ of its initial constant value, and then the FPLG meets the switching standards again, the

198 motor force of the LEM declines from $50 \%$ to $0 \%$ of its initial constant value, and then to a

199 resistance force. The immediately switching strategy means that the motor force of the LEM declines

200 immediately from $100 \%$ to $0 \%$ of its initial value and then to a resistance force. During the

201 intermediate process, when the "Immediately switching strategy" is applied, the Step Function

$202 \varepsilon_{2}(x)$ is expressed as follows:

$203 \varepsilon_{2}(x)= \begin{cases}0, & x<x_{1} \\ 1, & x \geq x_{1}\end{cases}$

And during the intermediate process, when the "Gradually switching strategy" is applied, the

205 Step Function $\varepsilon_{2}(x)$ is expressed as follows:

$206 \quad \varepsilon_{2}(x)= \begin{cases}0, & x<x_{1} \\ \frac{1}{2}, & x_{1} \leq x<x_{2} \\ 1, & x \geq x_{2}\end{cases}$

207 where, $x_{2}$ is the other switching position.

208 As our previous publications report [1], the thermodynamic equation of the in-cylinder gas 209 pressure changes in the cylinder has already been derived as:

$210 \quad \frac{d p}{d t}=\frac{\gamma-1}{V}\left(\frac{d Q_{c}}{d t}-\frac{d Q_{h}}{d t}\right)-\gamma \frac{p}{V} \frac{d V}{d t}$

211 Where $p$ is the pressure in the cylinder, $\gamma$ is the ratio of specific heats, $V$ is cylinder volume, $Q_{c}$ is the 212 heat released during the combustion process, and $Q_{h}$ is heat transfer loss, here is described based on 213 the Wiebe combustion heat release function [1]. 


$$
\left\{\begin{array}{l}
\frac{d Q_{c}}{d t}=a \frac{b+1}{C_{d}}\left(\frac{t-t_{s}^{b}}{C_{d}}\right) \exp \left(-a\left(\frac{t-t_{s}}{C_{d}}\right)^{b+1}\right) Q_{i n} \\
\frac{d Q_{h}}{d t}=h A_{c y l}\left(T-T_{w}\right)
\end{array}\right.
$$

215 Where $a$ and $b$ are shape factors, with the fitting value of 5 and 2 respectively [1,6], $C_{d}$ is the 216 combustion duration with a constant value of $5 \mathrm{~ms}, t_{s}$ is the time at which the combustion process 217 starts, $Q_{\text {in }}$ is the overall heat input for each cylinder in one running cycle, $h$ is the coefficient of heat 218 transfer, $A_{c y l}$ is area of the in-cylinder surface in contact with the gas, $T_{w}$ is the average surfaces 219 temperature of the cylinder wall.

220 The equation of the friction force is expressed as follows:

$221 \quad F_{f}=C_{f} \frac{d x}{d t}$

222 where $C_{f}$ is the viscosity friction coefficient $[1,9,37]$.

motor force to piston. As our previous publications report [1], the equation of the motor force is expressed as follows:

where, $k_{f}$ is the thrust coefficient of the motor, and $I$ is the current value in the coil of the motor. supplies a resistance force to piston. As our previous publications reports [1], the equation of the 230 resistance force is expressed as follows:

$$
F_{g}=k_{\mathrm{f}} \cdot k_{\varepsilon} \frac{1}{R_{\mathrm{S}}+R_{\mathrm{L}}+j \cdot L} \cdot \frac{\mathrm{d} x}{\mathrm{~d} t}
$$

232 Where, $k_{\varepsilon}$ is the coefficient of the electromotive force of the generator, $R_{S}$ is the resistance of the coil, $R_{L}$ is resistance of the external load, and $L$ is the inductance of the generator. 


\subsection{Model validation}

Previous investigation suggests that the FPLG was sensitive to external load changes [29-31].

Therefore, in order to explore the characteristics of the FPLG during the operation process, the FPLG was operated to work at a specific condition, and the input parameters value and external load value were constant for each cycle. The air-intake pressure was 1.2 bar, and the throttle opened at $40 \%$. The injected fuel mass was calculated based on the tested air mass flow for each operation cycle, the fuel injection system was controlled with an open-loop strategy. And the ignition position was set $27.5 \mathrm{~mm}$ away from the middle stroke. From the discussions above, the ignition timing, injection timing and fuel injection mass were not optimized for the best performance during the operation process [6].

Based on the test system of the FPLG prototype, the piston displacement and in-cylinder gas pressure were collected for analysis and the comparison between simulation results and experiment results were demonstrated [1]. Figure 7 shows the in-cylinder gas pressure of the simulation results and the experiment results in the starting process and the generating process, respectively. It is found that the simulation result and experiment result were similar whether at the starting process or generating process. As the maximum error between the in-cylinder gas pressure values of the simulation results and the experiment results was less than 5\%, indicating that the model was valid and can predict the performance of the FPLG during the operation process $[1,9]$. It is also obvious that the in-cylinder peak gas pressure at the starting process was larger than that at the generating process. This is because the input energy of the FPLG during the starting process comes from the chemical energy of the combustion of mixed gas and the electric energy provided by the LEM, while the input energy of the FPLG during the generating process only comes from the chemical energy of 
the combustion of the mixed gas.

\section{Test results and discussion}

\subsection{Piston dynamics}

Figure 8 illustrates the piston dynamics characteristics of the prototype during the stable generating process for one cycle, with the piston motion of the TRE compared in the same figure. It is observed that, with the same parameters, the piston motion of the FPLG was significantly different from that of the TRE $[4,9,42]$. For the FPLG, the piston decelerated during the compression stroke whereas it accelerated faster during the expansion stroke around the top dead centre (TDC) as demonstrated in Figure 8 (a). The piston movement of the FPLG shows limit-ring features during stable operation, as is demonstrated in Figure 8 (b). Compared with the TRE, the gradient of the limit-ring profile is larger during the compression and expansion strokes [9]. This is because the piston of the FPLG is not restricted by a crankshaft mechanism, its profile is determined by the forces acting on the piston, including force from the LEM, frictional force, and in-cylinder gas forces.

\subsection{Starting strategy of the starting process}

Based on the working principle of the FPLG, the starting process of the FPLG, the LEM runs as

a motor. The LEM supplies a motor constant force in the same direction with piston velocity, pushing piston to reciprocate until meeting the ignition conditions (a. the effective compression ratio is above

8 , b. the in-cylinder peak gas pressure is above 10 bar.), according to previous paper [8]. Therefore, during the starting process, different motor force determined different starting strategies. When choosing a lower motor force during the starting process, more time is required for the engine to be ignite successfully. This is the oscillation start-up strategy. When choosing a large motor force at the 
starting process, the piston can reach the condition for ignition after only several circulations.

Sometimes one circulation would be enough. This is one-time starting strategy.

The starting process was carried out with different motor forces from $50 \mathrm{~N}$ to $300 \mathrm{~N}$ in $50 \mathrm{~N}$ interval. The changes of compression ratios are shown in Figure. 9. With a fixed motor force, the compression ratio showed non-linear growing trend, and after several circulations, the compression ratio was stable. When the motor force at the starting process was smaller than $100 \mathrm{~N}$, no matter how many times of circulation, the engine cannot reach the compression ratio for ignition, which is 8 .

When the motor force at the starting process was larger than $300 \mathrm{~N}$, only one circulation can meet the compression ratio for ignition (the compression ratio was 8). By comparing the compression ratio with different motor forces, it is clear that the higher motor force in the starting process, the fewer time is required to meet the compression ratio for ignition.

In order to meet all the ignition conditions, apart from the compression ratio must reach 8 , the in-cylinder peak gas pressure must reach 10 bar. During the starting process, it is found that the simulation results and experiment results were similar, as shown in Figure 10. The error is because the gas leakage was ignored during the simulation process. From the Figure 10, it is also found that the changing trend of the peak in-cylinder gas pressure were the same as that of the compression ratio. With a fixed motoring force, the in-cylinder peak gas pressure showed non-linear growth, and after several circulations, the in-cylinder peak gas pressure stabilized. When the motor force was smaller than $100 \mathrm{~N}$ at the starting process, the in-cylinder peak gas pressure cannot meet the ignition condition. When the motor force was larger than $300 \mathrm{~N}$, one circulation alone can reach the in-cylinder peak gas pressure for ignition. And the larger the motor force, the sooner to meet the in-cylinder peak gas pressure for ignition. 


\subsection{Switching strategy of the intermediate process}

Based on the working principle of the FPLG, once the starting process was completed, the LEM was switched to the generator mode during the intermediate process. According to previous paper [6], different switching strategies (the gradually switching strategy and the immediately switching strategy) were applied during the intermediate process. In order to compare the engine performance with different switching strategies, in this paper the weighted average of 100 tested consecutive cycles is applied [6].

Figure 11 shows the comparison of the application of gradually switching strategy with immediately switching strategy during the intermediate process based on simulation results and experimental results respectively. The simulation results and the experimental results suggest that the piston parameters, such as the TDC and the peak velocity, decline gradually when the "gradually switching strategy" is applied. While those parameters decline immediately when "immediately switching strategy" is applied during the intermediate process. And the change of gradient of the parameters value when "gradually switching strategy" is applied is smaller than that when "immediately switching strategy" is applied. This is due to the lower changing rate of the motor force for the "gradually switching strategy". As a result, the "gradually switching strategy" is an optimal choice because it can help to achieve a smoother operation during the intermediate process [6].

Moreover, after the intermediate process, it is observed that the operation parameters are the same whether the "gradually switching strategy" or the "immediately switching strategy" are applied. And it is found that the values of operation parameters after the intermediate process were lower than those before the intermediate process. This is because that the input energy before the intermediate 
322 process the FPLG is larger than that after the intermediate process.

\subsection{Engine performance of the generating process}

Based on the working principle of the FPLG, the generating process of the FPLG, the LEM runs

as a generator. The data in Figure 12 shows the tested in-cylinder gas pressure. It was found that the

in-cylinder gas peak pressure for each operation cycle fluctuates between 42 bar and 50 bar randomly.

It means that the mixed gas in the cylinder combusted in every cycle according as cylinder pressure without combustion was reported to be less than 20 bar in our previous paper [40], thus the designed

FPLG can operates continuously without any misfire during the generating process. And the data in

Figure 13 indicates that the FPLG is operating in the generating process too, because the TDC of the piston of FPLG misfires within the cylinder is much smaller than them of FPLG during the stable generating process based on our previous analysis [8]. The FPLG is operating stably during the generating process, but there are cycle-to-cycle variations. According to the previous research on the FPLG working principle, the piston motion is not limited by mechanism, and peak in-cylinder gas pressure for each operation cycle fluctuates randomly, thus the piston TDC differs for each cycle, as shown in Figure 13. From what we have discussed above, the TDC of the piston and in-cylinder gas pressure fluctuated in every cycle, but it is observed that the FPLG could continue to operate in stable generating process.

The piston velocity-displacement profile is shown in Figure 14. The piston velocity-displacement ring state shows that the non-linear fluctuation is stable, and the input energy and consumption energy of the system remain in a dynamic balance, based on energy conservation law. As for the FPLG, the piston velocity-displacement ring suggests the stable cycle and the dynamic balance in the energy when the FPLG is operating during the stable generating process [36]. 
344 In addition, the piston velocity prior to the TDC is different from that after the TDC, as the piston 345 velocity after TDC is larger than the one before TDC. Thus, the fluctuations in the piston velocity 346 before and after the TDC show the difference in the compression and expansion processes of the 347 FPLG. The piston velocity-displacement cycle is in a central symmetry state when the velocity is 348 zero and the piston is in the middle stroke, and the velocity changing trend around TDC on both 349 sides is similar. engine performance, in this paper the weighted average of 100 tested consecutive cycles is applied [6]. According to the experimental results, the operation frequency of the FPLG is $24.1 \mathrm{~Hz}$ during the stable generating process. In order to research the engine performance of FPLG from experiment, we managed the synchronous acquisition of the piston displacement and in-cylinder gas pressure data. The data regarding the partial displacement and in-cylinder gas pressure was demonstrated in Figure 15. Because the experiment was subjected to potential disturbance from various factors, the accuracy of the test in-cylinder gas pressure data was affected, which will then influence the further calculations. Therefore, a filter was used. The engine pressure-volume diagram is shown in Figure 16.

The engine performance is then calculated based on the experimental results when the FPLG was in stable operation, in order to further analyze the energy conversion efficiency of the whole system.

(1) Indicated work

The engine indicated work in one operation cycle is the useful work of the working medium in 
366 the cylinder of one working cycle of the FPLG to the piston. The data can be acquired using the 367 pressure volume diagram shown in Figure 16, and the indicated work can be given by:

$368 W=\oint(p \cdot A) d x$

369 Where $W$ is the indicated work of a cylinder.

$370 \quad$ (2) Mean effective pressure

371 The indicated mean effective pressure refers to the indicated work of one cycle divided by the 372 cylinder working volume.

$373 \quad p_{\text {mean }}=\frac{W}{V_{s}}$

374 Where $p_{\text {mean }}$ is the indicated mean effective pressure of a cylinder, $V_{s}$ is the working volume in 375 cylinder.

$376 \quad$ (3) Indicated power

377 According to the calculation formula of indicated power, the indicated power of the FPLG can be 378 calculated by:

$379 P=2 \times W \times f$

380 Where $P$ is the indicated power of the FPLG, $f$ is operation frequency of the FPLG.

(4) Indicated thermal efficiency

According to the definition of indicated thermal efficiency, it can be obtained by:

$383 \quad \eta=\frac{W}{Q_{\text {fuel }}}$

384 Where $\eta$ is the indicated thermal efficiency of engine, $Q_{\text {fuel }}$ is input heat from fuel in one cycle.

385 The engine performance of the FPLG prototype based on experimental results was calculated 386 and shown in Table 2. 


\subsection{FPLG performance analysis during each operation process}

According to the introduction above, the working process of the FPLG consists of three processes: the starting process including two stages, the intermediate process from engine cold start-up to stable operation, and the generating process. But the performances of the FPLG were difference when compared to the FPLG operated in the stable generating process and the starting process including two stages, which the LEM ran as a motor. In order to compare the piston dynamics for different operation process, the average piston velocity-displacement profile of 100 tested cycles is drawn and shown in Figure 17.

It was found that the piston TDC, peak piston velocity and operation frequency of the FPLG during the generating process were smaller than those when operated during the second stage of the starting process, while much higher than those during the first stage of the starting process. The changing rate of piston velocity in both compression stroke and expansion stroke during the generating process is lower that during the second stage of the starting process. Because the FPLG operated at the second stage of the staring process, the LEM run as a motor supplies constant motor force to the piston, thus the input energy of the FPLG comes from both the chemical energy of the fuel and the electric energy provided by the LEM. While during the generating process, the input energy of the FPLG only comes from the chemical energy of the fuel. And during the first stage of the staring process without combustion, the input energy of the FPLG only comes from the LEM, without any contribution from the chemical energy.

The tested pressure volume diagram of the designed FPLG prototype in different process is shown in Figure 18, and the engine performance of the prototype is shown in table 3. As combustion does not take place on the first stage of the starting process, the pressure volume profile is not 
409 included in Figure 18.

\section{Conclusions}

This paper presents an investigation of the operation characteristics of FPLG from the starting

412 process to the generating process. The simulation results show a good agreement with the prototype

413 experimental results for each operation process. As for the operation characteristics of FPLG, the 414 conclusions are listed below:

415 (1) During the starting process, with a fixed motor force, the compression ratio and the in-cylinder 416 peak gas pressure showed non-linear growing trend respectively. After several operation cycles, 417 the compression and the in-cylinder peak gas pressure became stable respectively. When the

(2) During the intermediate process, the "gradually switching strategy" could help achieve a smoother operation because the piston parameters (piston TDC, peak piston velocity and in-cylinder peak gas pressure) declined gradually when it was applied. Moreover, after the intermediate process, it was observed that the operation parameters were the same whether the different switching strategies were applied. But the values of the operation parameters after the intermediate process were lower than those before the intermediate process whether the "gradually switching strategy" or the "immediately switching strategy" was applied.

(3) During the generating process, Cycle-to-cycle variations were observed in piston TDC and 
in-cylinder gas pressure. The piston displacement was similar with a sinusoidal wave. Compared with the TRE, the piston of the FPLG decelerated during the compression stroke whereas it accelerated faster during the expansion stroke around the TDC, and the piston stayed less time

(4) The experimental results showed that the operation frequency was $24.1 \mathrm{~Hz}$. The indicated work of for one cylinder was $60.7 \mathrm{~J}$, the indicated mean effective pressure was $31.1 \mathrm{bar}$, the engine indicated power was $2.9 \mathrm{~kW}$, and the indicated thermal efficiency was $37.3 \%$. The piston parameters and operation frequency of the FPLG during the generating process were smaller than those when operated during the second stage of the starting process, while much higher than those during the first stage of the starting process.

\section{Acknowledgement}

This project is supported by the Program of Introducing Talents of Discipline to Universities of China (B12022) and National Nature Science Foundation of China (51006010). We would like to thank the sponsors.

\section{References}

[1] Jia Boru, Zhengxing Zuo, et al. Development and validation of a free-piston engine generator numerical model. Energy Conversion and Management 2015; 91: 333-341. DOI:10.1016/j.enconman.2014.11.054.

[2] Qian Wang, Di Zhang, et al. Numerical simulation of catalysis combustion inside micro free-piston engine. Energy Conversion and Management 2016; 31: 243-251. DOI:10.1016/j.enconman.2016.01.035.

[3] C. Champagne, L. Weiss. Performance analysis of a miniature free piston expander for waste 
heat energy harvesting. Energy Conversion and Management 2013; 76: 883-892. DOI:10.1016/j.enconman.2013.08.045.

[4] Mikalsen R, Roskilly AP. A review of free-piston engine history and applications. Applied Thermal Engineering 2007; 27: 2339-52. DOI: 10.1016/j.applthermaleng.2007.03.015.

[5] Han Yongqiang, Kang Jianjian, et al. Performance evaluation of free piston compressor coupling organic Rankine cycle under different operating conditions. Energy Conversion and Management 2014; 86:340-348. DOI:10.1016/j.enconman.2014.05.041.

[6] Feng Huihua, Guo Chendong, Boru Jia, et al. Research on the intermediate process of a free-piston linear generator from cold start-up to stable operation: numerical model and experimental results. Energy Conversion and Management 2016; 122:153-164. DOI:10.1016/j.enconman.2016.05.068.

[7] Boru Jia, Andrew Smallbone, et al. Design and simulation of a two- or four-stroke free-piston engine generator for range extender applications. Energy Conversion and Management 2016; 111: 289-298. DOI:10.1016/j.enconman.2015.12.063.

[8] Boru Jia, Guohong Tian, Huihua Feng, et al .An experimental investigation into the starting process of free-piston engine generator. Applied Energy 2015; 157: 798-804. DOI:10.1016/j.apenergy.2015.02.065.

[9] Feng Huihua, Guo Chendong, Yuan Chenheng, et al. Research on combustion process of a free piston diesel linear generator. Applied Energy 2016; 161: 395-403. DOI:10.1016/j.apenergy.2015.10.069.

[10]Pescara R P. Motor compressor apparatus. 1928.

[11] Achten P A J. A review of free piston engine concepts. SAE Paper 941776, Society of 
Automotive Engineers 1994: 1836-1847.

[12]Dulpichet Rerkpreedapong. Field Analysis and Design of a Moving Iron Linear Alternator for Use with Linear Engine. Dissertation, West Virginia University; 1999.

[13]Cawthorne, W., Famouri, P., Clark, N. Integrated design of linear alternator/engine system for HEV auxiliary power unit. IEEE Int. Electric Machines and Drives Conf. 2001: 267-274.

[14]Subhash Nandkumar. Two-Stroke Linear Engine. Dissertation, West Virginia University, 1998.

[15]Clark N, Famouri P, Cawthorne W. Operation of a small bore two-stroke linear engine. 1998 Fall Technical Conference of The ASME Internal Combustion Engine Division Clymer, New York September 1998: 27-30.

[16] Atkinson C, Petreanu S, Clark N, et al. Numerical Simulation of a Two-Stroke Linear Engine-Alternator Combination. SAE Technical Paper 1999-01-0921; 1999.

[17]Famouri P, Cawthorne WR, Clark N etc. Design and testing of a novel linear alternator and engine system for remote electrical power system. Power Engineering Society 1999 Winter Meeting, IEEE, 10.1109/PESW.1999.747434.

[18] Van Blarigan, P., Paradiso, N. and Goldsborough, S.. Homogeneous Charge Compression Ignition with a Free Piston: A New Approach to Ideal Otto Cycle Performance. SAE Paper $982484 ; 1998$.

[19]Van Blarigan, P. and Goldsborough, S.. Free Piston Generator/Turbine Systems-Advanced Hybrid Systems, Proceedings of the 14th Annual U.S. Hydrogen Meeting: Energy Security through Hydrogen, National Hydrogen Association, March 4th-6th, Washington DC; 2003.

[20]P. Nemecek, M. Sindelka, O.Vysoky. Control of Two-stroke Free-piston Generator. The 6th Asian Control Conference; 2006. 
[21]Nemecek P, Sindelka M, Vysoky O. Modeling and control of linear combustion engine. Proc. of the IFAC Symposium on Advances in Automotive Control 2004: 320-325.

[22] Plsek S, Deutsch P, Vysoky O. Validation of the Linear Combustion Engine Model. Bratislava; 2007.

[23] Vysoky O. Linear Combustion Engine as Main Energy Unit for Hybrid Vehicles. Proceedings of Transtec Prague; 2007.

[24]Max E. FPEC, Free piston energy converter. Proceedings of the 21st electric vehicle symposium \& exhibition, EVS21, Monaco; 2005.

[25]Hansson J. Homogeneous Charge Compression Ignition with a Free Piston. Stockholm: Royal Institute of Technology; 2006.

[26]Fredriksson J, Denbratt I. Simulation of a two stroke free piston engine. SAE Paper, 2004, 2004-01-1871

[27]R. Mikalsen, A.P. Roskilly. Performance simulation of a spark ignited free-piston engine $\begin{array}{lllll}\text { generator. } & \text { Applied } & \text { Thermal } & \text { Engineering } & 2008 ;\end{array}$ DOI:10.1016/j.applthermaleng.2007.11.015.

[28]R. Mikalsen, A.P. Roskilly. The design and simulation of a two-stroke free-piston compression ignition engine for electrical power generation. Applied Thermal Engineering 2008; 28: 589-600. DOI:10.1016/j.applthermaleng.2007.04.009.

[29]R. Mikalsen, A.P. Roskilly. Coupled dynamic-multidimensional modeling of free-piston engine combustion. Applied Energy 2009; 86: 89-95. DOI:10.1016/j.apenergy.2008.04.012.

[30]Mikalsen R, Roskilly AP. A computational study of free-piston diesel engine combustion. Applied Energy 2009; 86: 1136-43. DOI:10.1016/j.apenergy.2008.08.004. 
519 [31] Mikalsen, R., and A. P. Roskilly. The control of a free-piston engine generator. Part 1: Fundamental analyses. Applied

Energy

2010; 87.4:

1273-1280.

[32] Mikalsen, R., and A. P. Roskilly. The control of a free-piston engine generator. Part 2: Engine dynamics and piston motion control. Applied Energy 2010;87.4: 1281-1287. DOI:10.1016/j.apenergy.2009.06.035.

[33]R. Mikalsen, E. Jones, A.P. Roskilly. Predictive piston motion control in a free-piston internal $\begin{array}{lllll}\text { combustion } & \text { engine. } & \text { Applied } & \text { Energy } & \text { 2010; }\end{array}$ DOI:10.1016/j.apenergy.2009.11.005.

[34] Xu, Zhaoping. Research on Internal Combustion-Linear Generator Integrated Power System and its Implementation. Dissertation, Beijing University of Science\&Technology; 2010.

[35] Xu, Zhaoping, Siqin Chang. Prototype testing and analysis of a novel internal combustion linear generator integrated power system. Applied Energy 2010; 87: 1342-1348. DOI:10.1016/j.apenergy.2009.08.027.

[36] Tian Chunlai. Research on Dynamics and Control Strategy of Free-piston Engine for Linear Generator. Dissertation, Beijing Institute of Technology; 2012.

[37] Mao J, Zuo Z, Liu D. Numerical simulation of a spark ignited two-stroke free-piston engine generator. Journal of Beijing Institute of Technology 2009; 18(3): 283-287.

[38] Mao Jinlong. Numerical Simulation and Experimental Analysis of Free-piston Linear Alternator. Dissertation, Beijing Institute of Technology; 2011.

[39]Wang Mengqiu. Study on Simulation and Experiments of Starting Process of Spark-ignited FPEG. Dissertation, Beijing Institute of Technology; 2014. 
541 [40]Boru Jia, Zhengxing Zuo, Huihua Feng, et al. Investigation of the starting process of free-piston 542 engine generator by mechanical resonance. The 6th International Conference on Applied

[44]Boru Jia, Andrew Smallbone, Huihua Feng, et al. A fast response free-piston engine generator numerical model for control applications. Applied Energy 2016; 162: 321-329. DOI: 10.1016/j.apenergy.2015.10.108.

[45]Jia B, Zuo Z, Feng H, Tian G, Roskilly AP. Development approach of a spark-ignited free-piston engine generator. No. 2014-01-2894. SAE Technical Paper, 2014.

[46]Miao Yuxi, et al. Research on the Combustion Characteristics of a Free-Piston Gasoline Engine Linear Generator during the Stable Generating Process. Energies, 9(8):655, 2016. 
579 Nomenclature

FPLG Free piston linear generator

FPEC Free-piston energy convertor

FPE Free-piston engine

TRE Traditional reciprocating engine

LEM Linear electric machine

HCCI Homogeneous charge compression ignition

TDC Top dead center 


\begin{tabular}{|c|c|}
\hline$E C U$ & Integrated electronic control unit \\
\hline$P F I$ & Port fuel injection \\
\hline$F_{f}$ & Friction force $(\mathrm{N})$ \\
\hline$F_{m}$ & Motor force when the LEM runs as a motor $(\mathrm{N})$ \\
\hline$F_{g}$ & Resistance force when the LEM runs as a generator $(\mathrm{N})$ \\
\hline$\varepsilon_{1}(x)$ & Step Function \\
\hline$\varepsilon_{2}(x)$ & Step Function \\
\hline$m$ & Moving mass of the piston and connecting rod $(\mathrm{kg})$ \\
\hline$x$ & Piston displacement (mm) \\
\hline$x_{1}$ & Switching position (mm) \\
\hline$x_{2}$ & Switching position (mm) \\
\hline$A$ & Top surface area of the piston \\
\hline$p$ & In-cylinder gas pressure (bar) \\
\hline$p_{L}$ & Pressure in the left cylinder (bar) \\
\hline$p_{R}$ & Pressure in the right cylinder (bar) \\
\hline$\gamma$ & Ratio of specific heats (-) \\
\hline$V$ & Cylinder volume $\left(\mathrm{m}^{3}\right)$ \\
\hline$Q_{h}$ & Heat transfer loss $(\mathrm{J})$ \\
\hline$Q_{c}$ & Heat released from the combustion process $(\mathrm{J})$ \\
\hline$a$ & 5 \\
\hline$b$ & 2 \\
\hline$C_{d}$ & Combustion duration $(5 \mathrm{~ms})$ \\
\hline$t_{s}$ & The time at which the combustion process starts $(\mathrm{J})$ \\
\hline$Q_{\text {in }}$ & The overall heat input for each cylinder in one running cycle $(\mathrm{J})$ \\
\hline$h$ & The coefficient of heat transfer \\
\hline$A_{c y l}$ & The area of the in-cylinder surface in contact with the gas $\left(\mathrm{m}^{2}\right)$ \\
\hline$T_{w}$ & The average surfaces temperature of the cylinder wall $(\mathrm{K})$ \\
\hline$C_{f}$ & Viscosity friction coefficient (-) \\
\hline$k_{f}$ & Thrust coefficient of the motor (N/A) \\
\hline$I$ & Current value in the starter coil of the motor (A) \\
\hline
\end{tabular}




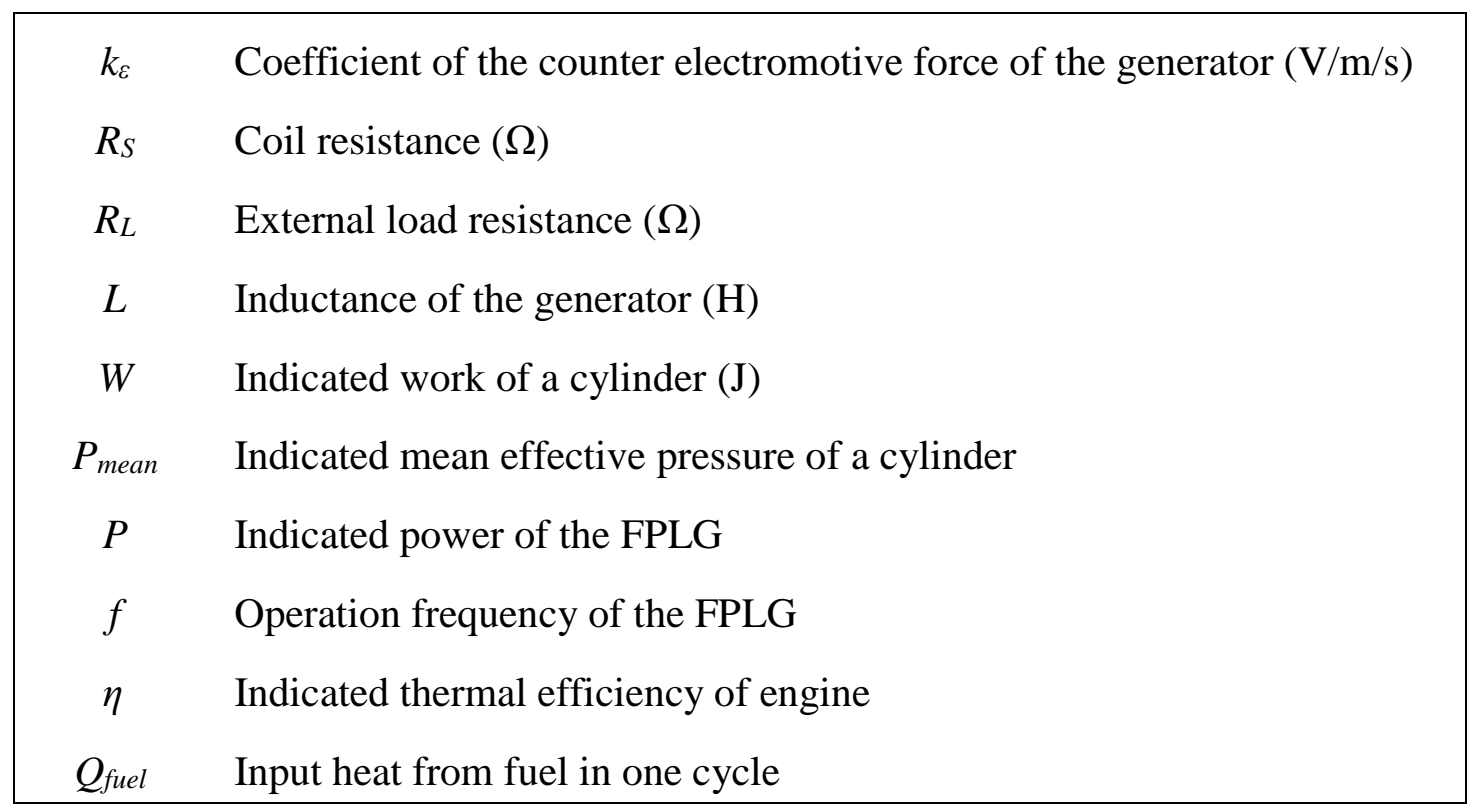




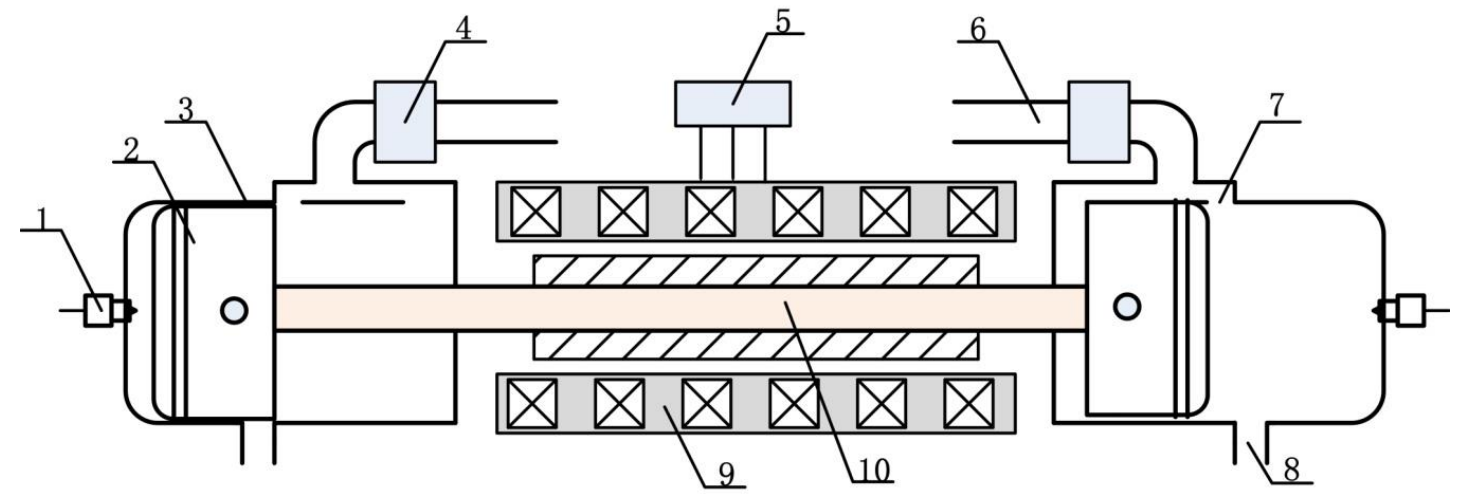

1. Spark plug; 2. Piston; 3. Cylinder; 4. Fuel injector; 5. External Load; 6. Air-intake tube; 7. Scavenging port; 8. Exhaust port; 9. Stator; 10. Connecting rod

Figure 1. The prototype structure of the FPLG

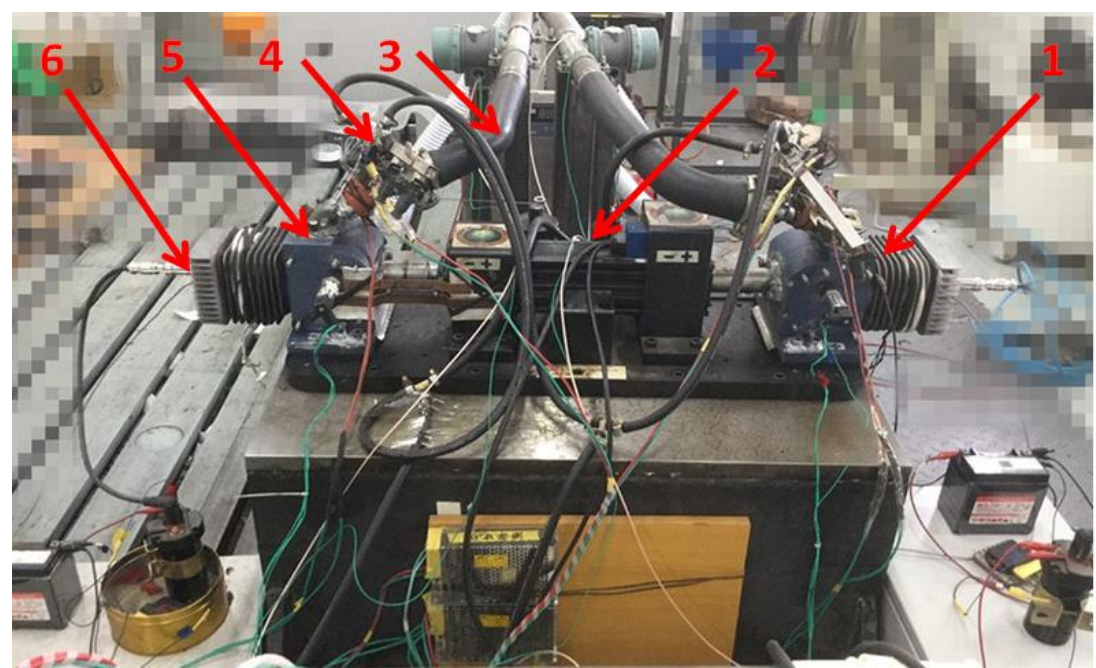

1. The cylinder; 2. The LEM; 3.Air-intake system; 4. Fuel injection system; 5. Scavenging box; 6. Ignition system

Figure 2. The physical prototype of the FPLG 


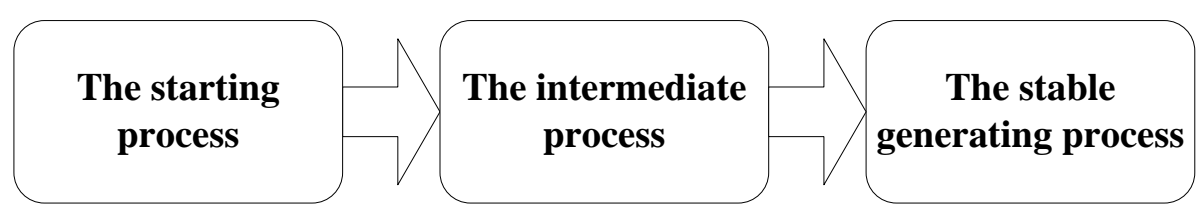

Figure 3. Operation processes of the FPLG

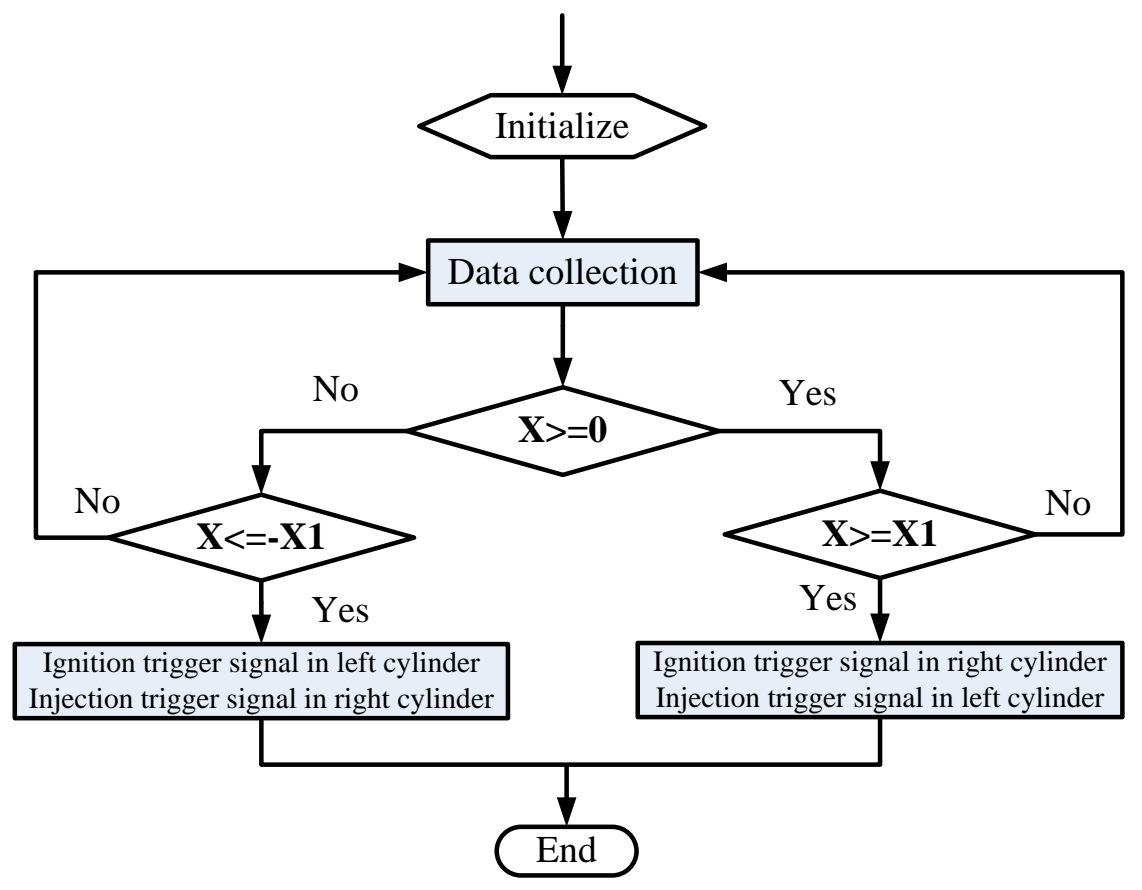


Figure 5. Controlling system and test system of the FPLG prototype

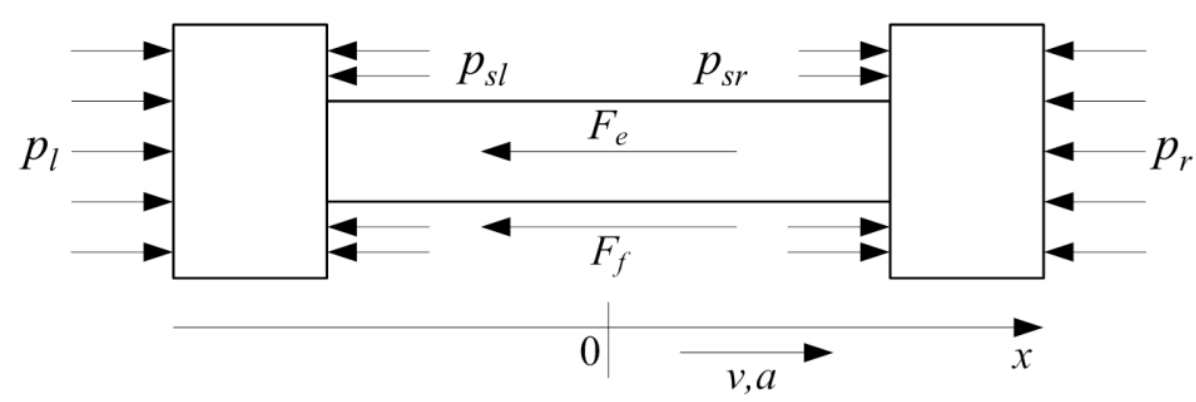

Figure 6. Forces acting on the pistons of the FPLG 


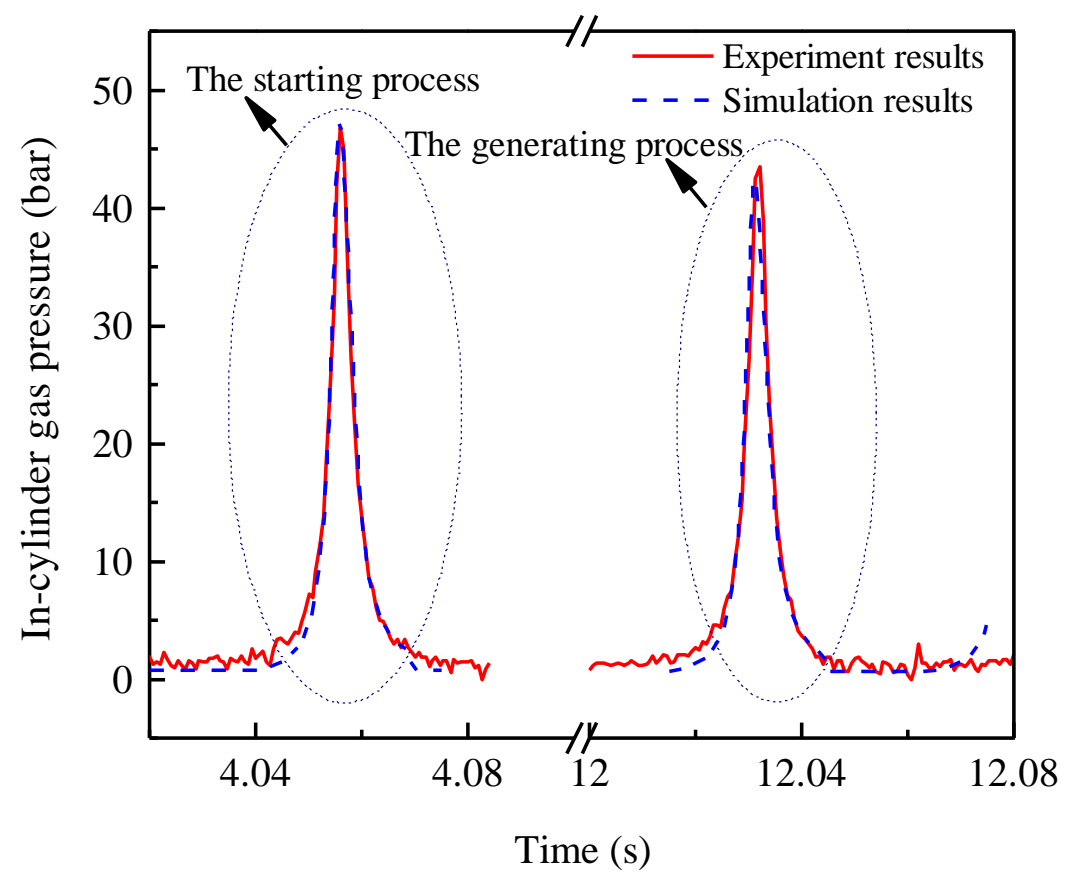

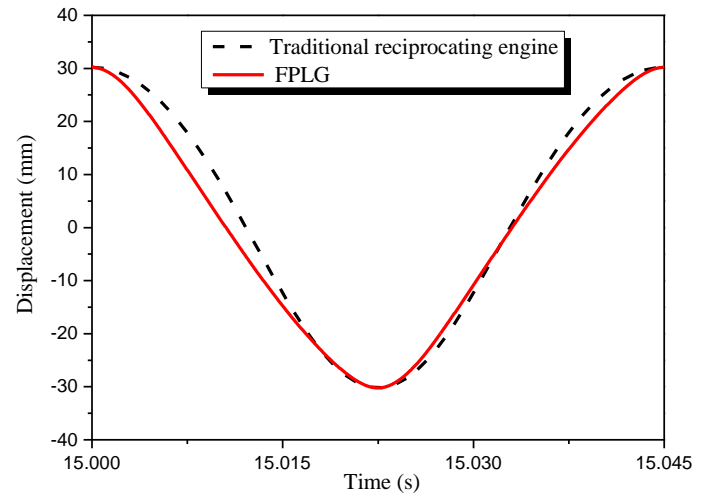

632

633

(a) Piston displacement profile

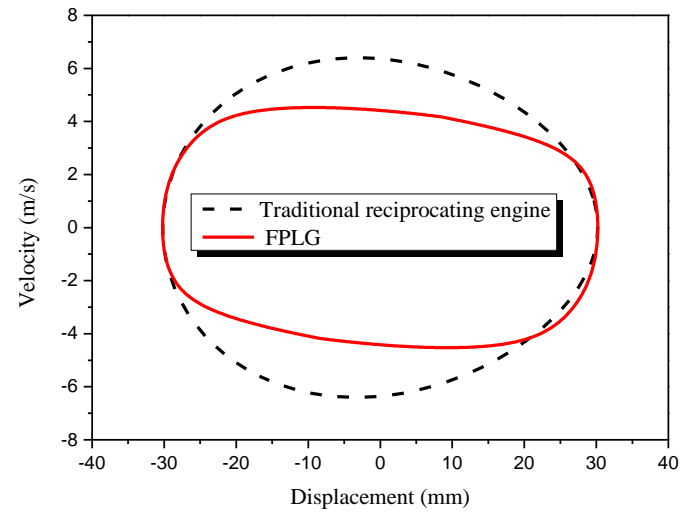

(b) Piston velocity-displacement profile

Figure 8. Comparison of piston dynamic characteristics of the FPDLG and the traditional reciprocating engine 

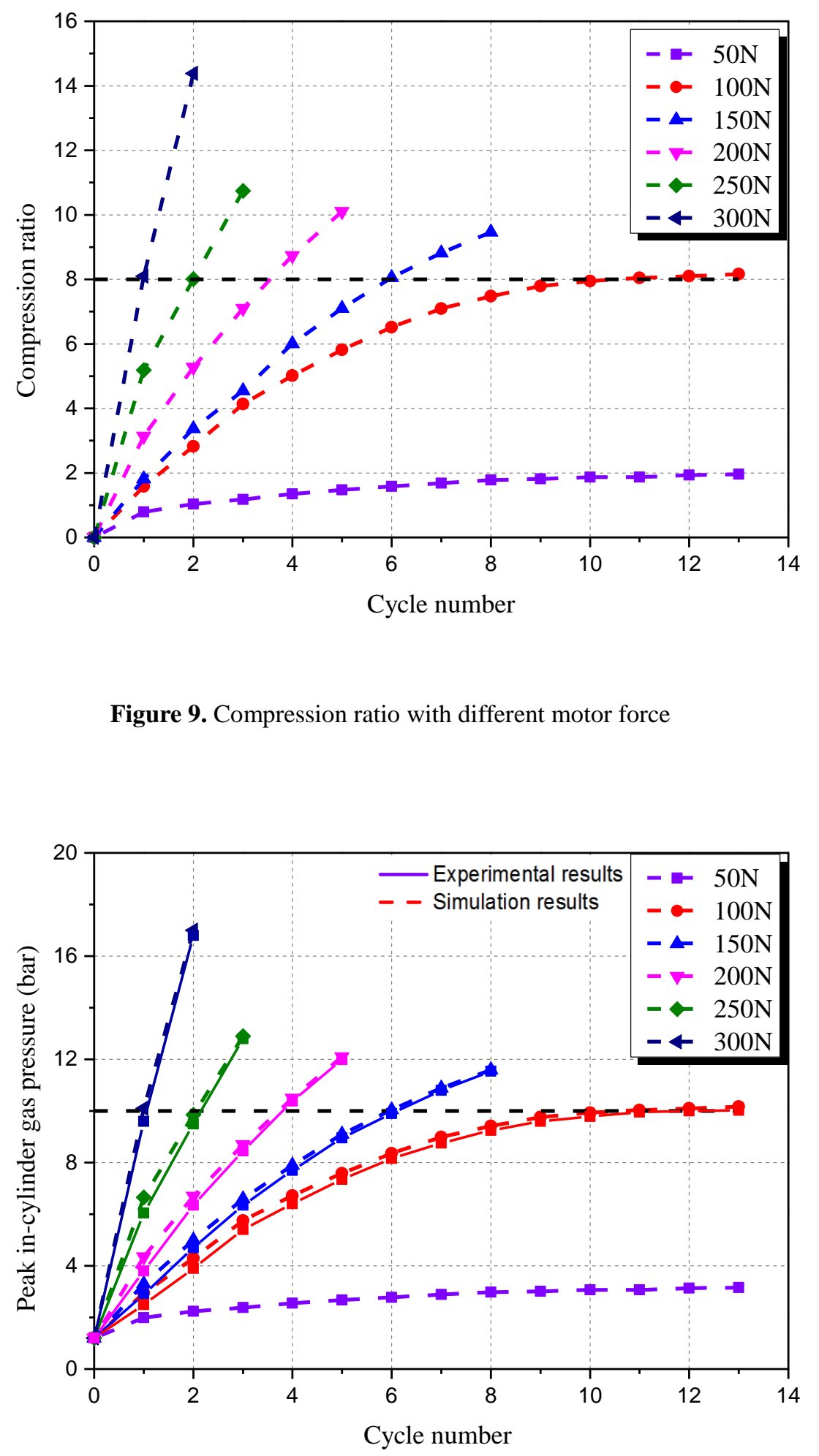

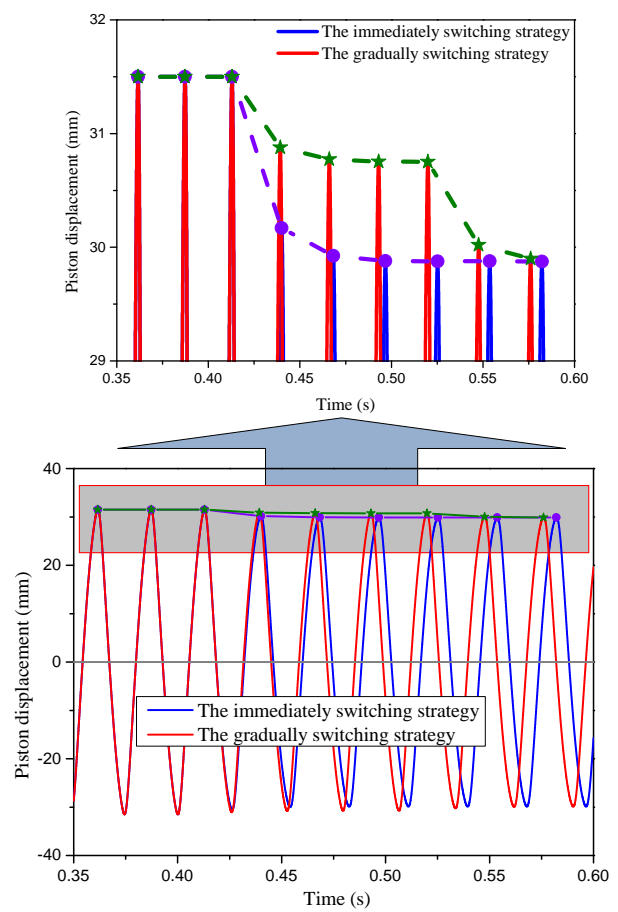

642

643

(a) Piston position profile of the FPLG (Simulation results)

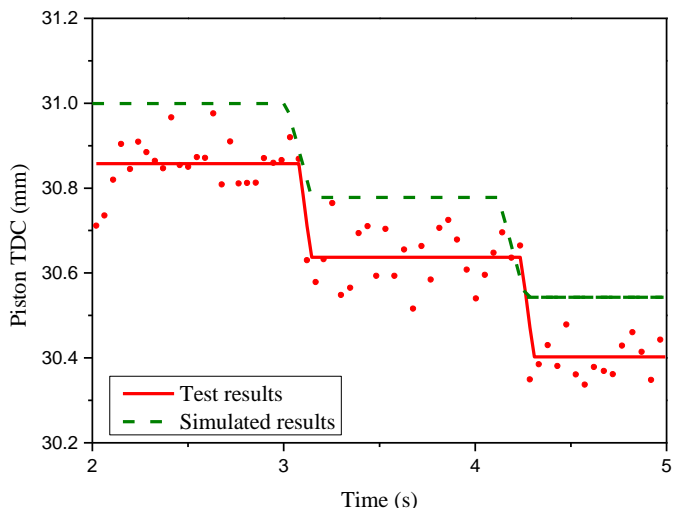

644

645

(a) Piston TDC of the FPLG (Experimental results)
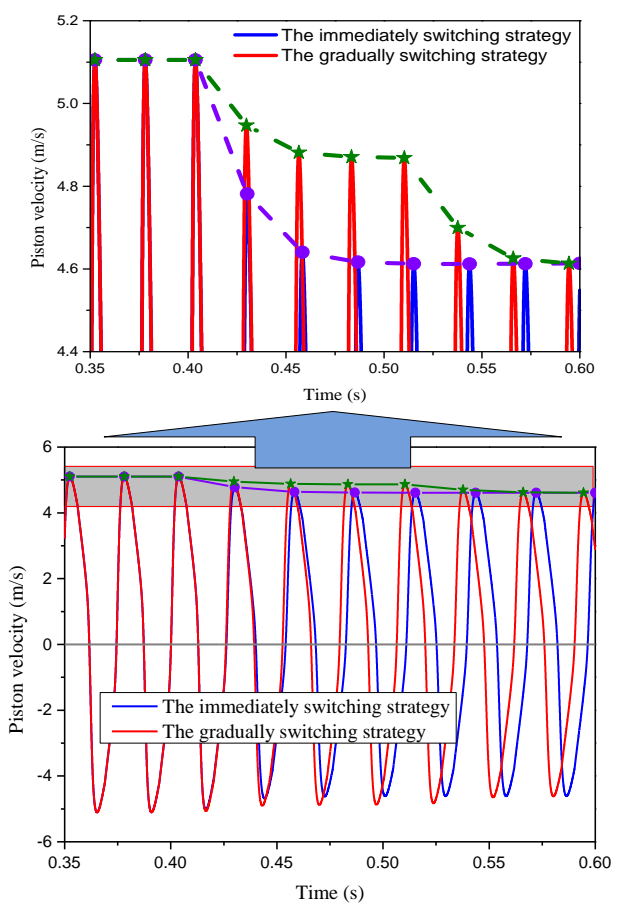

(b) Piston velocity profile of the FPLG (Simulation results)

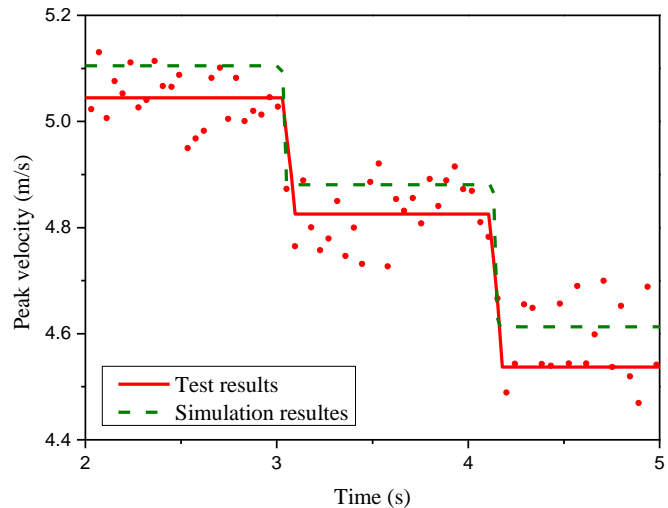

(b) Piston peak velocity of the FPLG (Experimental results)

Figure 11. Comparison with different switching strategies during the intermediate process from simulation results and experimental results 


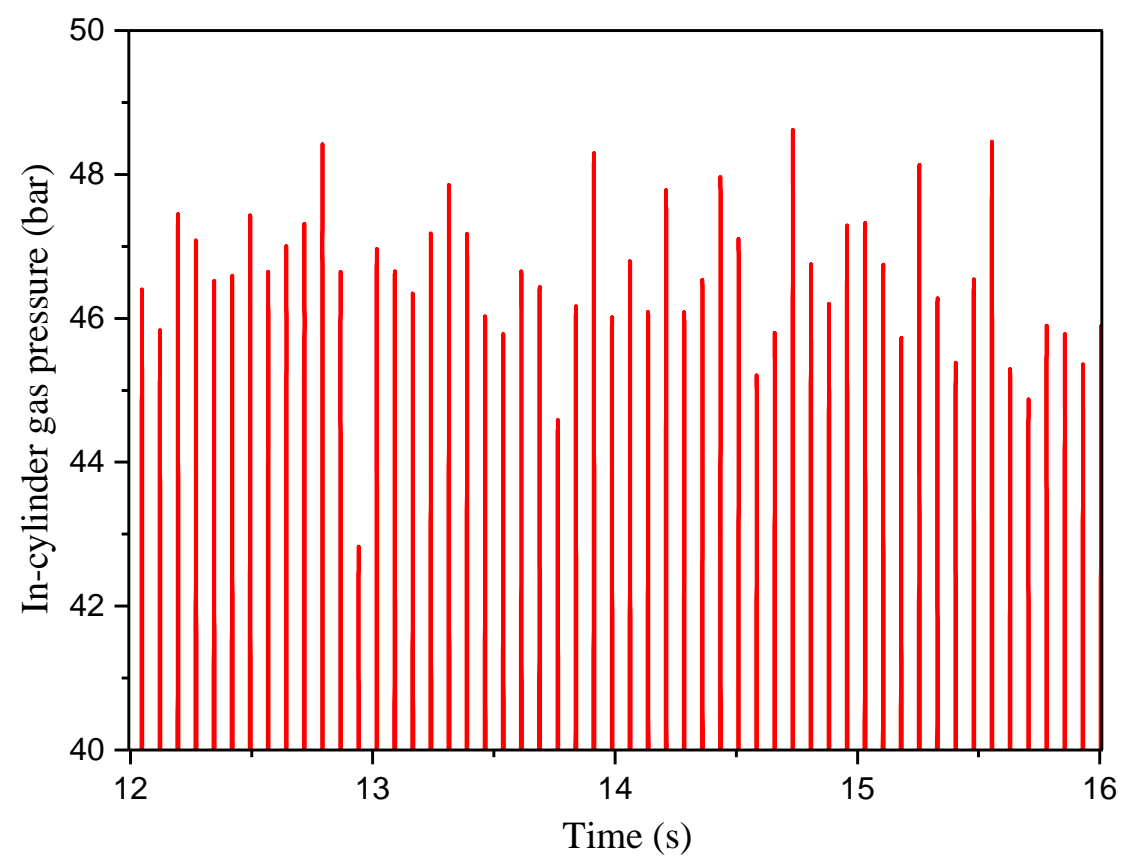

651

Figure 12. In-cylinder gas pressure for several cycles from experimental results

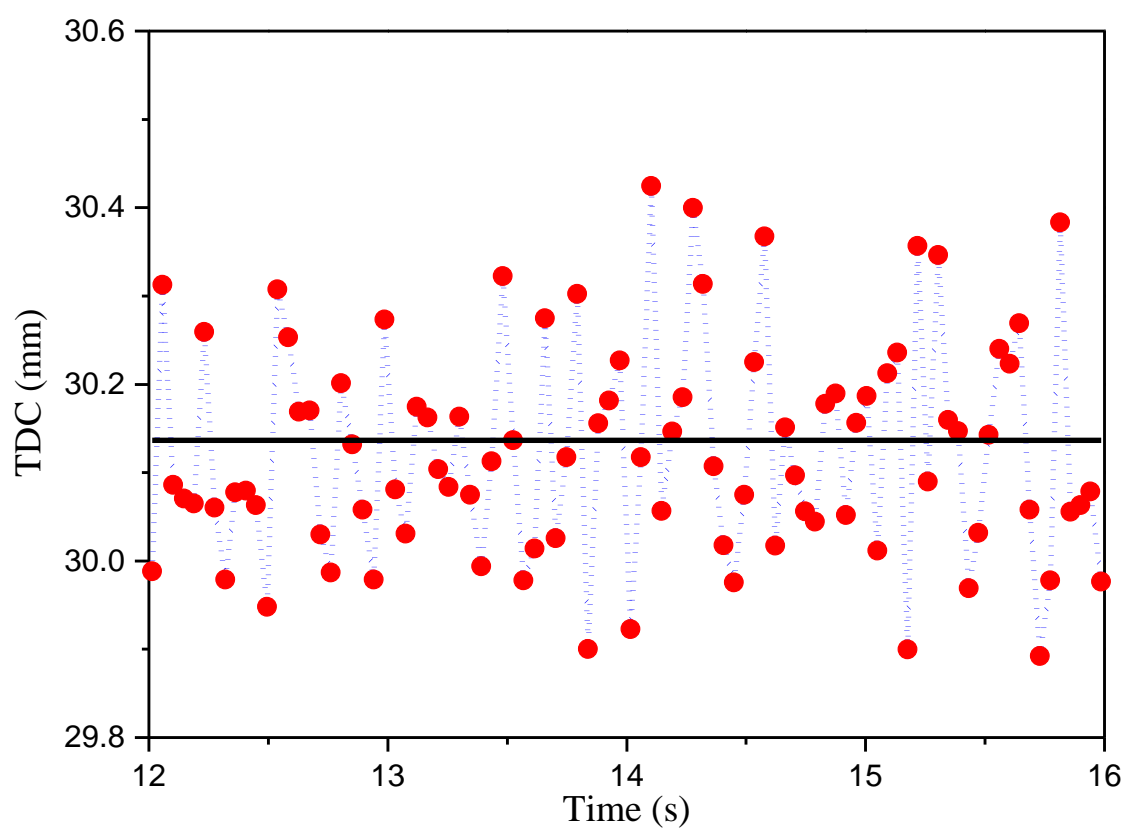

Figure 13. Piston TDC for several cycles from experimental results 

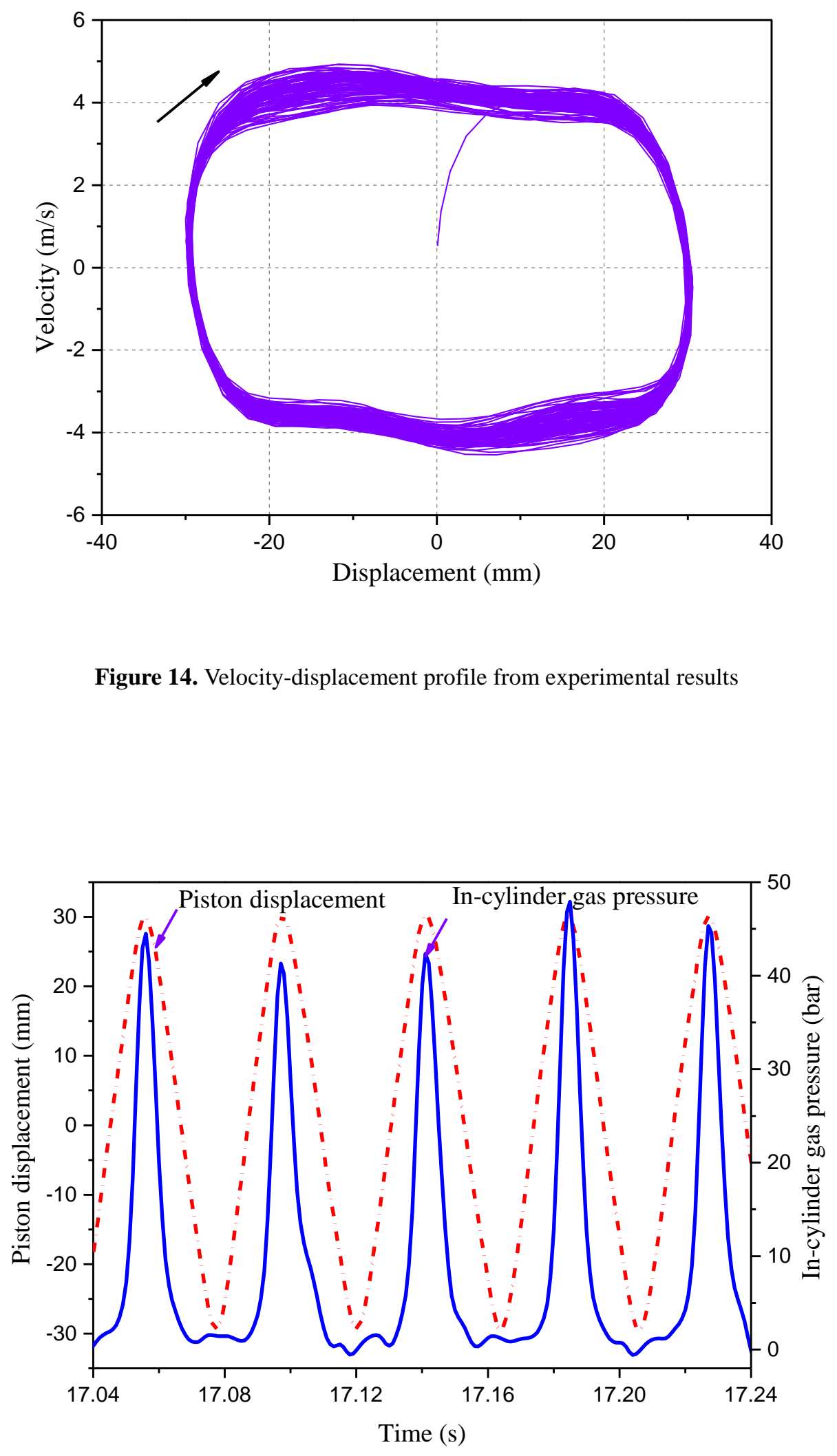

Figure 15. Partial in-cylinder gas pressure and displacement profile from experimental results 


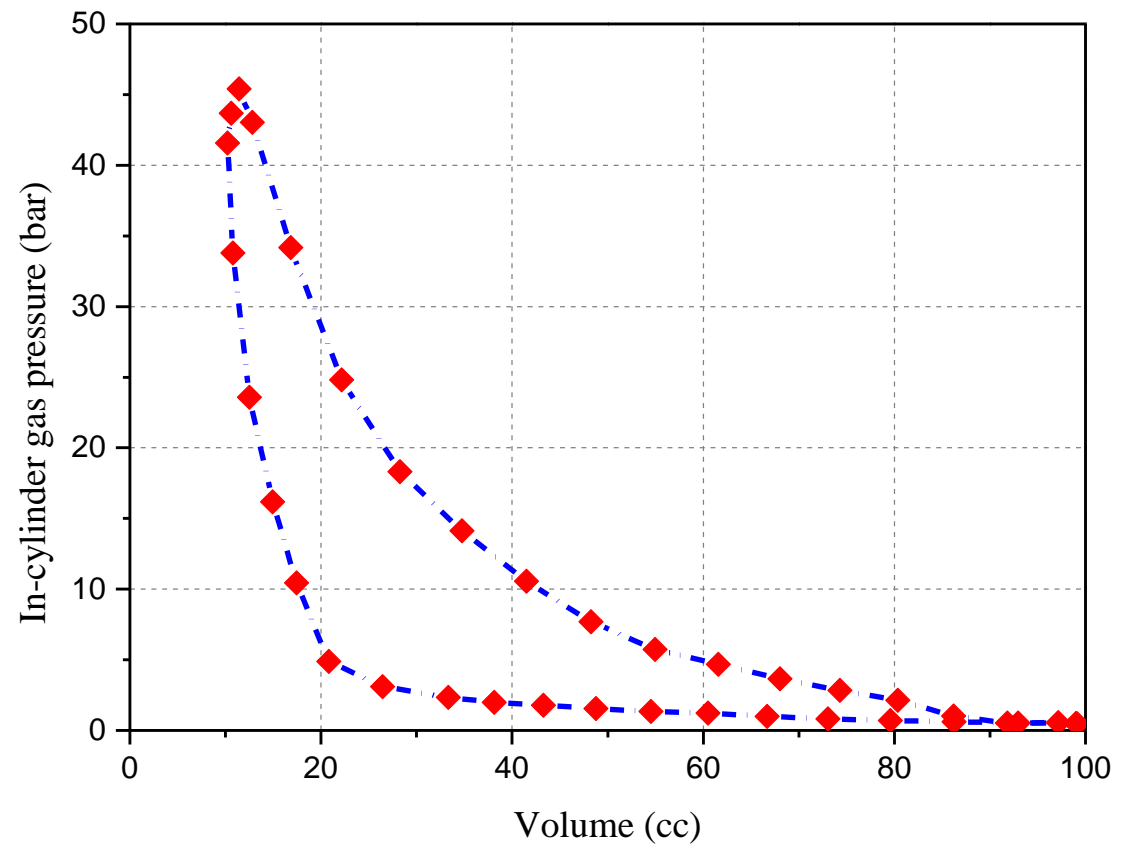

660

Figure 16. The pressure volume diagram of the designed FPLG prototype from experimental results

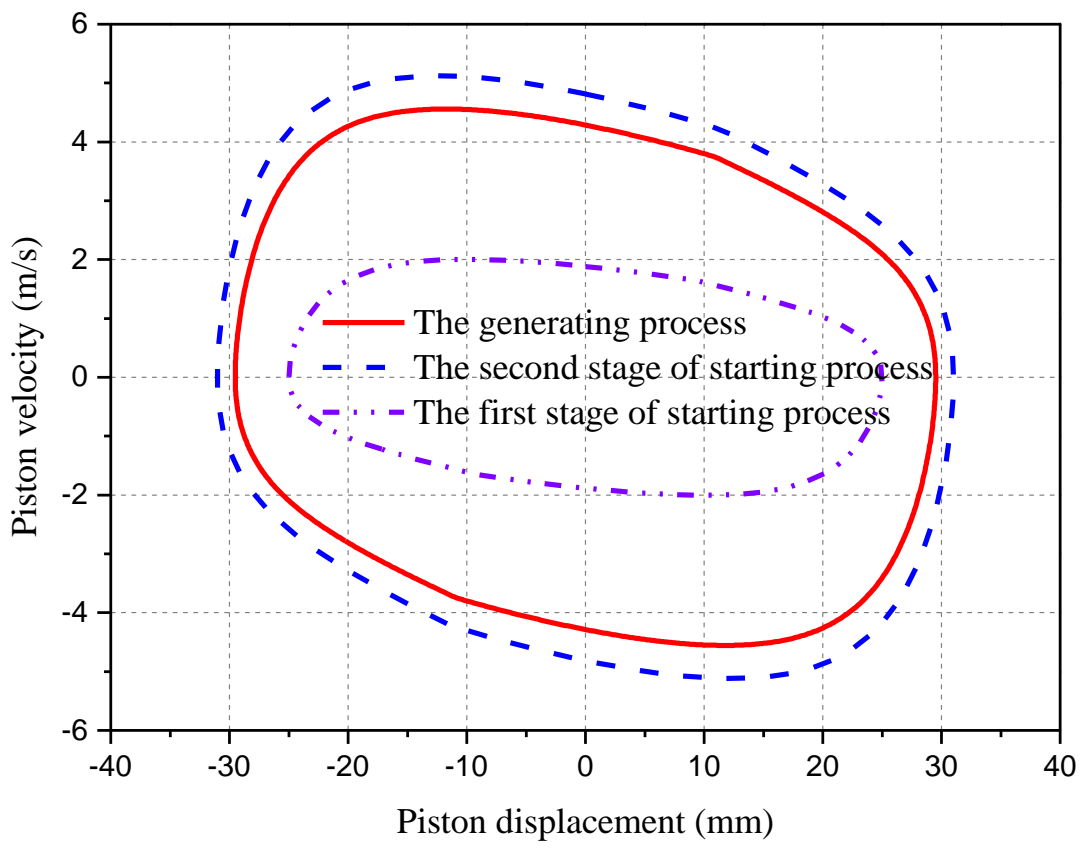

Figure 17. Comparison of velocity-displacement profile of FPLG operated in different process from experimental results 


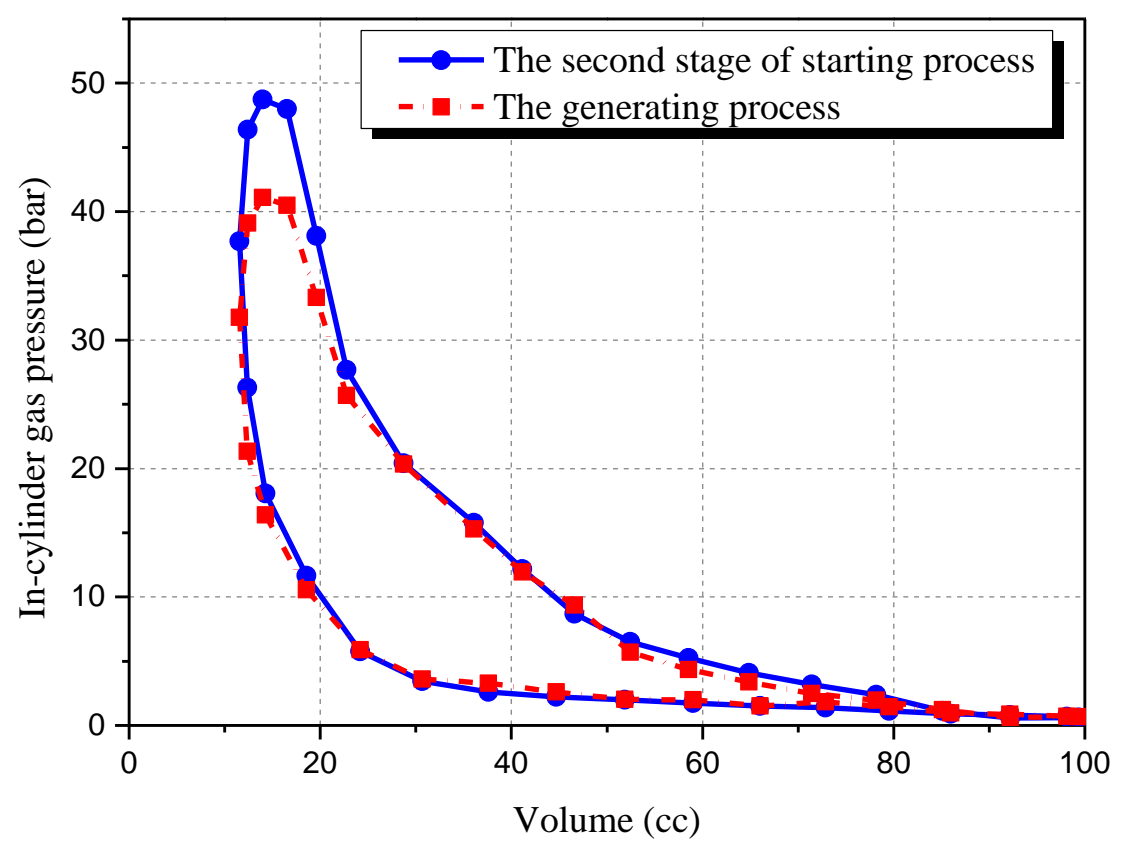

665

666 Figure 18. Comparison of the pressure volume diagram of FPLG operated in different process from experimental results 667 


\begin{tabular}{lc}
\hline Parameters & Values \\
\hline Bore (mm) & 52.5 \\
Effective stroke (mm) & 34.0 \\
Total stroke (mm) & 68.0 \\
Air-intake pressure (bar) & 1.2 \\
Piston and connecting rod mass (kg) & 5.0 \\
Thrust force constant (N/A) & 74.4 \\
Coil resistance ( $\Omega$ ) & 14.0 \\
External load resistance $(\Omega)$ & 28.0 \\
\hline
\end{tabular}

Table 2 The FPLG performance parameters from experimental results

\begin{tabular}{lc}
\hline Parameters & Value \\
\hline Frequency of the FPLG $(\mathrm{Hz})$ & 24.1 \\
Peak piston velocity (m/s) & 4.5 \\
Indicated work of a cylinder $(\mathrm{J})$ & 60.7 \\
Mean indicated pressure of a cylinder (bar) & 31.1 \\
Indicated power of the FPLG (kW) & 2.9 \\
Indicated thermal efficiency of engine & $37.3 \%$ \\
\hline
\end{tabular}


Engine performance

Frequency of the FPLG $(\mathrm{Hz})$

Peak piston velocity $(\mathrm{m} / \mathrm{s})$

Indicated work of a cylinder (J)

Indicated power of the FPLG $(\mathrm{kW})$

Indicated thermal efficiency of engine
The second stage of starting process

25.2

4.9

65.6

3.3

$42.4 \%$
Generating process

24.1

4.5

60.7

2.9

$37.3 \%$ 